\title{
A HERMENÊUTICA FILOSÓFICA NA ATD
}

\author{
THE PHILOSOPHICAL HERMENEUTICS THE DTA
}

Rodrigo Eder Zambam ${ }^{1}$

\begin{abstract}
Resumo: O presente artigo tem como objetivo identificar na Análise Textual Discursiva (ATD) características e influências teóricas da hermenêutica filosófica. Trabalhamos com a hipótese de que a ATD possa conter em sua metodologia princípios da hermenêutica filosófica. Para alcançarmos a finalidade proposta, retomaremos alguns conceitos da hermenêutica filosófica presente na obra de Hans-Georg Gadamer, a saber: linguagem (logos), mundo de sentido, experiência e diálogo. Com base nestes conceitos, faremos um estudo do artigo de Moraes e Galiazzi intitulado: "Avalanche reconstrutivas: movimentos dialéticos e hermenêuticos de transformação no envolvimento com a Análise Textual Discursiva". Este escrito relata que o "movimento da ATD é o movimento em direção à hermenêutica, com valorização de pré-compreensões como modos de chegar a entendimentos mais complexos". O entendimento mais complexo se afasta da proposta reducionista, simplificadora e objetivadora da ciência moderna e pensa uma metodologia sempre em movimento. Aqui encontramos a influência e a aproximação com a hermenêutica filosófica.
\end{abstract}

Palavras-chave: Análise textual discursiva; Diálogo; Hermenêutica filosófica; Linguagem; Método.

Abstract: This paper aims to identify characteristics and theoretical influences of Philosophical Hermeneutics in the research methodology of the Discursive Textual Analysis (DTA). The hypothesis is that the DTA may include principles of Philosophical Hermeneutics in its methodology. In order to achieve the objective, some concepts of Philosophical Hermeneutics found in Hans-Georg Gadamer's work, i.e. language (logos), world of sense, experience and dialogue, are reviewed. Based on these concepts, the paper entitled "Reconstructive avalanches: dialectic and hermeneutic movements of transformation intertwined with the Discursive Textual Analysis", by Moraes and Galiazzi, is studied. It states that "the DTA movement is the one towards Hermeneutics, which values preconceptions as ways to achieve more complex understanding". The most complex understanding moves away from the reductionist, simplified and objectified proposal of modern science and aims at a methodology that is always in movement. That is where the influence and the proximity with Philosophical Hermeneutics is found.

Keywords: Discursive Textual Analysis; Dialogue; Philosophical Hermeneutics; Language; Method.

\section{Introdução}

O presente artigo resulta de inquietações e provocações presentes na metodologia da Análise Textual Discursiva (ATD). Tais inquietações dizem respeito à influência, direta ou indiretamente, da hermenêutica filosófica na motivação de tal metodologia e no procedimento analítico do discurso a ser estudado. Ora, estudar o discurso requer necessariamente a relação entre dois mundos, a saber: o mundo do pesquisador e o mundo do investigado. O primeiro tem como desafio e responsabilidade central escutar as

\footnotetext{
${ }^{1}$ Doutor em Educação Ambiental pela Universidade Federal do Rio Grande (FURG). Mestre em Filosofia pela Universidade do Vale do Rio dos Sinos (UNISINOS). Licenciado em Filosofia pela Universidade de Passo Fundo (UPF). Professor Adjunto de Filosofia da FURG, Rio Grande, Brasil. E-mail: rodrigozambam@gmail.com
} 
diversas vozes presentes nesse discurso, para proceder e estruturar as categorias que lhe servirão como base de seus estudos e interpretações. Parece que, nesse complexo movimento interpretativo, a hermenêutica filosófica teorizada pelo filósofo alemão HansGeorg Gadamer, encontra-se presente. A hipótese que apresentamos como norte de nossa escrita é que a ATD tem em sua égide alguns princípios da hermenêutica filosófica. Vamos em busca desse fundamento teórico no texto, "Avalanche reconstrutivas: movimentos dialéticos e hermenêuticos de transformação no envolvimento com a Análise Textual Discursiva". Perceber a aproximação com a ontologia hermenêutica presente em Gadamer.

Para muitos leitores de Gadamer e conhecedores da ATD, a tentativa de aproximação das duas teorias pode soar estranho pela crítica que a hermenêutica filosófica faz aos procedimentos científicos que visam a separação e a dominação dos conceitos, ou melhor, quer tornar a verdade um resultado seguro e objetivo. Para evitar tal estranhamento, cabe esclarecer alguns pontos: i: Defende-se que a ATD não tem a pretensão de verdade última presente nas ciências particulares, a saber: a objetividade como critério de verdade; ii: No texto central aqui analisado, percebe-se muitos autores presentes nas referências pesquisadas que estão direta ou indiretamente ligados à hermenêutica filosófica, a saber: Grondin, Habermas, Heidegger, Stein e outros. Isso nos dá fortes indícios de que a proposta da ATD não visa a aproximação com a objetividade extrema como princípio último; iii: os autores da ATD possuem clareza das críticas feitas à ideia de verdade das ciências positivas. Com isso, a ATD está enredada conceitualmente e metodologicamente com os princípios da hermenêutica filosófica.

Nos parece que a ATD, apesar de buscar separar o texto em unidades de significados para a melhor compreensão, não tem como objetivo último o domínio absoluto da compreensão, do significado do texto. Há um acontecer da interpretação entre o pesquisador e o texto a ser analisado. "Neste movimento de interpretação do significado atribuído pelo autor exercita-se a apropriação das palavras de outras vozes para compreender melhor o texto". (MORAES; GALIAZZI, 2006, p. 118). Ela possui como preocupação a ontologia do pesquisador e do pesquisado, a historicidade e a existencialidade como algo intransponível. Esses são conceitos fundamentais da hermenêutica filosófica que sustentam o conceito de linguagem, horizonte dessa teoria. A professora Maria do Carmo Galiazzi, provocadora desta escrita e teórica da ATD, em suas aulas, usa uma expressão que cabe para defender esta aproximação: muitas vezes, a 
análise do texto nos "derruba". Neste contexto, interpreta-se o verbo "derrubar" com a ideia de não fechamento, de surpresa com a interpretação.

\begin{abstract}
Análise Textual Discursiva consiste não apenas em apropriar-se de uma metodologia de análise para produzir resultados de pesquisas, mas implica simultaneamente transformações do pesquisador, desafiando-o a assumir pressupostos de natureza epistemológica, ontológica e metodológica, com superação de modelos de ciência deterministas e com valorização dos sujeitos pesquisadores como autores das compreensões emergentes de suas pesquisas. (MORAES; GALIAZZI, 2016, p. 240).
\end{abstract}

O objetivo deste artigo não é explicar a análise da ATD. Para isso, já temos uma vasta e rica bibliografia. O desafio é percebermos traços da hermenêutica filosófica que se encontram na ATD. Ao lermos os textos da ATD com o entendimento da hermenêutica filosófica, essa última se faz presente como condição de possibilidade para que o pesquisador atinja a compreensão do texto a ser estudado e evite cair nas amarras metodológicas das pesquisas positivas.

Para cumprir o objetivo desse texto e alcançarmos a hipótese proposta, dividiremos o texto da seguinte forma: na primeira parte resgataremos alguns conceitos importantes da hermenêutica filosófica para orientar o leitor que não está familiarizado com a teoria. Num segundo momento, analisaremos alguns conceitos da ATD que estão diretamente relacionados à proposta da hermenêutica filosófica. O leitor perceberá que esse processo se dará de forma simultânea, apesar da tentativa didática de explicar alguns conceitos em momentos distintos. Tratando-se de um artigo, é sabido as limitações de espaço que a escrita nos impõe. Portanto, faremos algumas provocações indicando possíveis leituras que possam contribuir com o debate e o aprofundamento de futuros escritos e diálogos que porventura venham a ocorrer acerca do assunto.

\title{
2 Hermenêutica Filosófica
}

A hermenêutica ${ }^{2}$ filosófica, apesar de toda a influência de Martin Heidegger (1889-1976), tem sua proposta teorizada na grande obra de Hans-Georg Gadamer (19002002). Em Verdade e Método I, ele faz uma longa teorização acerca da hermenêutica, do método científico, da estética, da história, da existencialidade humana, da historicidade, etc, para finalmente chegar ao conceito central de sua filosofia: a linguagem. Na esteira

\footnotetext{
2 "O primeiro registro da palavra 'hermenêutica' como título de livro data do ano de 1654, em Dannhauer. Desde então distinguimos entre uma hermenêutica teológico-filológica e uma hermenêutica jurídica." (GADAMER, 2004b, p. 93).
} 
dessa proposta hermenêutica ${ }^{3}$, encontra-se a crítica ao conceito de verdade presente na base da ciência moderna que está ancorada na metodologia das ciências positivas a qual rege grande parte da estrutura moderna de pesquisa. A Filosofia e a Educação acabam sendo influenciadas pelo objetivismo presente na modernidade, esquecendo do ser humano como presença, mergulhado em sua historicidade e em sua temporalidade. Gadamer retoma este debate destacando a preocupação com o "esquecimento do Ser" presente no método moderno de busca pela verdade. A hermenêutica filosófica encontrase além de um reducionismo metódico, de um radicalismo em prol de uma objetividade positiva.

Aos pesquisadores da ATD e que buscarão aprofundar a aproximação com a hermenêutica filosófica, é importante perceber a proposta transformadora que se encontra no título de sua obra. Verdade e Método é uma clara crítica ao caminho proposto pela modernidade de busca pela verdade. Outra questão importante é o que encontramos no subtítulo da obra. Aqui se revela, talvez, a ideia central de sua hermenêutica, a saber: a hermenêutica ser filosófica. Nas palavras de Flickinger temos a seguinte explicação:

Verdade e Método, a obra mestra de Hans-Georg Gadamer, tem como subtítulo o que, na verdade, fora seu título original: "Elementos de uma hermenêtica filosófica". Nessa formulação Gadamer abre-nos o cerne de sua convicção filosófica. Pois, ao invés de utilizar-se do termo "Filosofia Hermenêutica" como seria de se esperar na continuidade do pensamento de Martin Heidegger - o filósofo fala-nos de uma "hermenêutica filosófica". E marca, assim, o contraponto à expectativa da época, já que adscreve à hermenêutica o ser sujeito da expressão, juntando-lhe, na predicação, o adjetivo "filosófica". Além de assim distanciar-se da corrente principal do século $\mathrm{XX}$, que segue argumentando nos trilhos da ideia iluminista da racionalidade instrumental, Gadamer expressa aí uma suspeita em relação a toda fundamentação teórica do saber que negligencia a experiência ontológica primordial, em que mergulhamos no nosso relacionamento imediato com o mundo (2000, p. 27).

A verdade, nos moldes da ciência moderna, visa a experiência positiva em detrimento da experiência negativa fundamentada a partir do diálogo hermenêutico. Denomina-se "diálogo hermenêutico" por se tratar do encontro entre dois mundos. Esse encontro pode-se dar em várias circunstâncias, a saber: na leitura de um livro, numa peça de teatro, num diálogo na sala de aula, na tradução de um texto e, inclusive, na reflexão central de nossa proposta, a saber: no exercício da ATD. Esta pesquisa deve necessariamente ter como um de seus pilares a consciência hermenêutica. $\mathrm{O}$ que isso

\footnotetext{
3 'Foi quando Heidegger formulou o conceito de uma 'hermenêutica da facticidade', impondo - em contraposição à ontologia fenomenológica da essência de Husserl - a tarefa paradoxal de interpretar a dimensão 'imemorial' (Schelling) da existência e inclusive a própria existência como 'compreensão' e 'interpretação', ou seja, como um projetar-se para possibilidades de si próprio. Nesse momento, alcançouse um ponto no qual o caráter instrumentalista do método, presente no fenômeno hermenêutico, teve de reverter-se à dimensão ontológica (GADAMER, 2004b, p. 103).
} 
significa? Saber que, ao estar analisando a fala dos entrevistados, não se está tendo um simples contato com um objeto com vistas à pura exploração objetiva das informações. O conteúdo da pesquisa carrega o mundo de sentido, os preconceitos da condição de sere-estar-no-mundo. Aqui se encontra a responsabilidade ética de quem conduz a pesquisa.

O compromisso ético com o outro assumindo a experiência hermenêutica enquanto exercício de pesquisa tendo presente o mundo de sentido dos envolvidos na mesma, aparece com nitidez na análise textual discursiva. "O movimento da ATD é o movimento em direção à hermenêutica, com a valorização de pré-compreensão como modos de chegar a entendimentos mais complexos." (MORAES; GALIAZZI, 2016, p. 243). Aqui destaca-se a preocupação com a existencialidade, com a historicidade, com os preconceitos dos pesquisados e do pesquisador. A manifestação, o acontecimento, as revelações desta complexa trama existencial se dão naquilo que destacamos como central da hermenêutica filosófica, a saber: a linguagem. Dessa forma, na sequência dessa citação, aparece esse conceito em destaque: "Nisso o pesquisador vai além de análises de caráter semiótico e semântico, para atingir interpretações de caráter hermenêutico, contextualizadas e históricas, com intenso envolvimento e autoria do pesquisador. (Ibidem, p. 243). Ir além da análise semiótica e semântica significa compreender a linguagem como a manifestação do mundo de sentido, carregando o verdadeiro e obscuro significado do ser.

Para perseguirmos a compreensão e a interpretação dessas importantes áreas de pesquisa, sugere-se como exercício para entendermos este movimento hermenêutico presente na ATD, a compreensão de alguns conceitos centrais da hermenêutica filosófica. Por uma questão puramente didática, apresentaremos a explicação desses conceitos em momentos distintos mesmo sabendo que eles estão inteiramente conectados. Tal característica fica clara no decorrer do texto.

\section{Linguagem}

De certo que a compreensão do que é linguagem representa uma das coisas mais obscuras com que já se deparou a reflexão humana (GADAMER, 2004a, p. $\left.383^{4}\right)$.

Como destacamos acima, Gadamer admite que compreender a linguagem é um desafio para o ser humano. Isto se deve ao fato de sermos, desde sempre, linguagem;

\footnotetext{
${ }^{4}$ A paginação está de acordo com a obra original "Wahrheit und Methode".
} 
estamos tão próximos dela que sua compreensão nos escapa por estar nela todo o nosso modo de ser. Mas, como compreender este conceito no contexto da hermenêutica filosófica para percebermos sua importância no movimento da ATD? Nos parece necessário retomar a origem deste conceito no contexto do pensamento gadameriano.

A linguagem encontra-se na base da hermenêutica filosófica. Deve-se compreendê-la para além de um reducionismo lógico, de uma estrutura gramatical ou de uma ferramenta ${ }^{5}$ de comunicação. Gadamer, em Verdade e Método I, faz todo um percurso teórico preparatório para, na terceira e última parte, dedicar-se ao tema da linguagem. Esta, compreendida como $\log o s$, como manifestação do mundo, como experiência ontológica. Na perspectiva da hermenêutica filosófica, a linguagem só tem sentido de ser quando pensada a partir da revelação do ser. Como nos coloca Gadamer, “o ser que pode ser compreendido é linguagem." (2004a, p. 478). E a compreensão de linguagem encontra-se afastada do reducionismo lógico presente na hermenêutica clássica.

Linguagem tem sua origem na palavra grega $\log o s^{6}$. Ao longo da história da Filosofia, esse conceito teve muitos significados e tem em Aristóteles um dos autores que problematiza e influencia seu significado ao longo da história colocando o homem como único ser que possui logos. Nas palavras de Gadamer: "Na verdade, a palavra significa também e sobretudo: linguagem." (2004b ${ }^{7}$, p. 146). Por ter linguagem, o ser humano tem a capacidade de julgar o que é justo e injusto, útil ou inútil ou prejudicial. Pode pensar e falar $^{8}$. Tem a capacidade de se comunicar e assim pensar de forma comum tornando possível a convivência em sociedade. Ao comunicar-se, revela seu modo de ser que carrega sua historicidade e sua existencialidade, acontecer do horizonte do passado e do presente.

Não há como pensarmos o mundo fora da linguagem ${ }^{9}$. Ele só existe a partir do momento que se revela na linguagem. Ao participarmos de um diálogo hermenêutico ou

\footnotetext{
5 “A linguagem não é nenhum instrumento, nenhuma ferramenta. Pois uma das características essenciais do instrumento é dominarmos seu uso, e isso significa que lançamos mão e nos desfazemos dele assim que prestou seu serviço." (GADAMER, 2004b, p. 148-149).

6 "É em Aristóteles a definição clássica do homem como o ser vivo que possui logos. Na tradição do Ocidente, essa definição foi canonizada com a forma: o homem é o animal racional, o ser vivo racional, o ser que se distingue de todos os outros animais pela capacidade de pensar. A palavra grega logos foi traduzida no sentido de razão ou pensar." (GADAMER, 2004a, p. 146).

${ }^{7}$ A paginação está de acordo com a obra original "Wahrheit und Methode II".

${ }^{8}$ Cf. GADAMER, 2004 b, p. 146.

9 “Acontece que a compreensão da linguagem não se reduz à captação intelectual, por um sujeito, de um contexto objetivável e isolado; ela resulta também, da mesma forma, da pertença a uma tradição em
} 
adotarmos uma postura de pesquisa com as bases metodológicas da hermenêutica filosófica, o pesquisador tem que estar aberto à escuta e ao diálogo. Caso contrário, seu objetivo não será atingido.

\begin{abstract}
Não só o mundo é mundo apenas quando vem à linguagem, como a própria linguagem só tem sua verdadeira existência no fato de que nela se representa o mundo. A originária humanidade da linguagem significa, portanto, ao mesmo tempo, o originário caráter de linguagem do estar-no-mundo do homem. Precisamos seguir essa relação entre linguagem e mundo, para alcançarmos um horizonte adequado para o caráter de linguagem da experiência hermenêutica (GADAMER, 2004a, p. 447).
\end{abstract}

Na esteira desta compreensão é que encontramos a ontologia hermenêutica. Para compreender a linguagem a partir dos conceitos da hermenêutica filosófica, é essencial estar disposto a se distanciar do entendimento da linguagem como simples estrutura lógica-gramatical ou retroceder ao entendimento de uma origem da linguagem buscando qual foi a primeira palavra proferida pelo ser humano. Esse é um exercício totalmente inútil. "É uma grande ilusão pensar que a criança fala uma palavra, a primeira palavra. Foi uma insensatez querer descobrir a linguagem originária isolando crianças e deixandoas crescer totalmente incomunicáveis..." (GADAMER, 2004b, p. 149). A hermenêutica filosófica compreende o ser humano desde sempre presente na linguagem. Toda a experiência ontológica necessariamente se apresenta na linguagem e "uma linguagem compreende-se apenas quando nela se vive", diz Gadamer. Viver na linguagem é compreender que desde sempre somos linguagem, nos manifestamos na linguagem, nosso mundo é linguagem. Sem linguagem, não teríamos mundo e, portanto, só tem mundo quem tem linguagem por ser nela que o ser se manifesta. Como coloca Heidegger, a linguagem é "a casa do ser" e por isso é nela que a verdadeira experiência acontece.

Essa é a marca universal do ser humano, pois não há homem sem linguagem e, do mesmo modo, não há acesso humano ao mundo que não seja através da linguagem. Desse modo, o mundo (humano) é sempre mundo de sentido, mundo compreensível, mundo de linguagem (ALMEIDA, 2002, p. 203).

A verdadeira experiência que é negligenciada pelas ciências particulares fundamentadas nas bases da proposta moderna, é a que se apresenta no diálogo hermenêutico. O Sócrates contemporâneo nos apresenta as bases que visam resgatar o Ser que se apresenta na linguagem e tem seu auge no diálogo vivo fruto da experiência negativa, a experiência ontológica radical ${ }^{10}$. O que seria esse diálogo vivo? Segundo Flickinger, “(...) é só no diálogo vivo que o 'ser para a linguagem’ encontra seu campo

continuada formação, isto é, da pertença a uma conversação, a partir da qual, unicamente, o que foi expresso adquire para nós consistência e significado.” (GRONDIN, 1999, p. 197).

${ }^{10}$ Cf. FLICKINGER, 2010, p. 116. 
de experiência primordial" (2010, p. 116). É no diálogo que os mundos se encontram e possibilitam a ampliação do mundo de sentido, ou seja, a ampliação da compreensão acerca do assunto pesquisado.

A linguagem revela e oculta a experiência ontológica do ser humano; através dela temos acesso ao mundo de sentido, à condição de finitude. As experiências negativas revelando as frustrações, os arrependimentos, os traumas presentes nas compreensões que surgem na linguagem. Nela revela-se o "suor" e o "sangue" da experiência existencial. Desrespeitar a condição histórica e existencial é perder sua verdadeira essência enquanto condição de possibilidade de acesso ao mundo, acesso ao sentido existencial da condição de ser-e-estar-no-mundo.

Um dos erros presente na filosofia da consciência é ter negligenciado a experiência ontológica existente na linguagem. Gadamer nos diz que a modernidade teve "preconceito dos preconceitos". Isto significa que o ser humano é dotado de preconceitos frutos da sua condição existencial, da condição de estar “jogado" em um mundo e dele se constituir. Respeitar essa condição é ter presente que, o que vem à fala ao escutarmos ${ }^{11}$ alguém ou lermos sua obra filosófica, pedagógica, literária etc., não é um objeto de manipulação, mas uma obra fruto de um acontecimento ontológico. Não pode ser manipulado e usado como uma simples ferramenta e depois descartado ao término de uma etapa de estudos. Esse contato deve ser estruturado a partir de uma interpretação que tenha a dimensão dialógica como estruturante da metodologia adotada. Ter presente a dimensão ontológica e existencial da linguagem e perceber nela a revelação autêntica do ser, ou seja, da visão e do pensamento humano, requer a postura altruísta para com o outro afastando-se da relação objetivista da ciência ${ }^{12}$.

A proposta da hermenêutica filosófica é situar o ser humano no mundo, na história e na linguagem e não como senhor de si, separado dos demais entes. Somente situando o ser humano nessa dimensão finita que conseguimos pensar sua dimensão ontológica e perceber na linguagem a revelação de sua autêntica experiência. "É no médium da

\footnotetext{
11 “O escutar, o prestar atenção, abre-nos não apenas o acesso a um determinado conteúdo, pelo qual nos vemos desafiados a reconsiderar nossas próprias convicções e supostas certezas; ele abre, mais ainda, o acesso ao outro, à outra pessoa e seu modo de refletir e de agir, como que a um questionamento permanente que quer ser levado a sério, tanto em termos teóricos, quanto em termos práticos" (FLICKINGER, 2010, p. 43).

12 Ao comentar acerca da interpretação, Richard Palmer nos diz: “'A ciência manipula as coisas e desiste de viver nelas', diz-nos o falecido fenomenologista francês Maurice Merleau-Ponty. Isto resume numa frase o que aconteceu à interpretação literária americana. Esquecemos que a obra literária não é um objeto manipulável, completamente à nossa disposição; é uma voz humana que vem do passado, uma voz à qual temos de certo modo que dar vida. O diálogo, e não a dissecação, abre o universo da obra literária. A objectividade desinteressada não é adequável à compreensão de uma obre literária” (1989, p. 18).
} 
linguagem que ocorre toda a nossa experiência do mundo, e a consciência do limite da linguagem é consciência também da nossa temporalidade; por isso a hermenêutica filosófica estrutura-se como ontologia e metafísica da finitude" (ROHDEN, 2002, p. 259260).

Cada palavra pertence a um conjunto de sentido e revela o mundo da qual pertence. A fala dos participantes de uma pesquisa tem sentido ao estar relacionada com o todo. Tentar compreendê-la fora dessa estrutura filosófica é incorrer no reducionismo lógico da filosofia da consciência. A linguagem tem poder, pertence a uma história, a uma tradição e nesta dinâmica faz ressoar o todo da língua a que pertence. A compreensão acontece se tivermos consciência desta dinâmica viva da linguagem. "Somente o meio da linguagem, por sua referência ao todo dos entes, pode mediar a essência histórico-finita do homem consigo mesmo e com o mundo (GADAMER, 2004a, p. 461).

\section{Mundo de sentido}

Dialogamos com a tradição por ela ser algo "vivo", escreve Gadamer. Ao pensarmos na condição existencial do ser humano, dentro de uma perspectiva hermenêutica, não há separação do ser humano com o mundo. O falar proporciona a revelação e a ocultação do mundo de sentido por manifestar a condição de ser-e-estarno-mundo. "Todo o falar humano é infinito no sentido de que abriga em si uma infinidade de sentido a ser desenvolvida e interpretada" (GADAMER, 2004a, p. 462). A interpretação do falar é a interpretação da revelação do Ser presente na linguagem. Por isso o respeito, ou seja, a postura ética de abertura e da disponibilidade de escutar o que o outro tem a nos dizer. A partir do momento em que nos colocamos na experiência de escuta, temos que ter claro que o outro está aberto a revelação de sua existencialidade, de seu mundo de sentido. A ATD, na sua análise, trabalha diretamente com o encontro dos mundos de sentidos, com a experiência finita, com a condição existencial dos participantes da pesquisa, inexoravelmente inseridos no horizonte de sentido.

A definição de "mundo" presente na hermenêutica filosófica chama a atenção para a necessidade de tomarmos cuidado com a postura radical da metodologia moderna de pesquisa, acerca do esquecimento da condição ontológica de compreensão que forma nosso horizonte de sentido. Resgatar a consciência de nossa historicidade abandonada pela postura ingênua da crença na fé metodológica e objetivista. "A consciência histórica é guardiã do Ser que sempre precisa ser compreendido; nela se apreende a própria 
consciência da finitude.” (ALMEIDA, 2002, p. 277). Adotar a postura calculadora da ciência moderna, é esquecer das condições ontológicas e da manifestação do Ser presente na linguagem; é esquecer que a relação entre os mundos de sentido (no caso da ATD, entre o pesquisador e o sujeito da pesquisa), é a fusão dos horizontes de sentido. Este é corolário do acontecer existencial que conduz, desde sua gênese, a interpretação. “(...) $a$ fusão de horizontes que se deu na compreensão é o genuíno desempenho e produção da linguagem." (GADAMER, 2004a, p. 383).

A relação com o mundo proposta pela hermenêutica filosófica, não é a busca pela verdade última, pela descoberta, pela decodificação das informações que insistem em se ocultar às investidas da razão observadora. É a experiência entendida no sentido de acontecimentos, ou seja, o sujeito que se relaciona com o todo que o cerca, com o todo que constitui a sua compreensão. Dessa forma, a compreensão do mundo nunca se restringe em ideias cristalinas e fechadas, mas mantêm sempre a abertura para novas experiências e aprendizados.

A compreensão deriva da abertura a um mundo de sentido, da condição de estar num mundo e de pertença a uma tradição. "A pertença a uma tradição é a expressão concreta de seu ser no mundo; e a partir dessa tradição e dos pré-conceitos que leva essa tradição, cada ser-aí projeta toda compreensão do passado, expresso num texto" (PÉREZESTÉVEZ, 2013, p. 187-188). Toda a experiência de um ser pertencente a um lugar apresenta seu acesso ao mundo na linguagem com seus preconceitos, com sua finitude revelando sua condição existencial, sua condição finita. Escutar o outro, ler suas colocações é fazer a experiência de mergulhar na complexidade da linguagem, ou seja, ter contato com a casa do ser. Interrogar seus próprios preconceitos. Essa experiência hermenêutica é grandiosa por revelar a riqueza existencial do ser humano que se revela na linguagem, no diálogo hermenêutico, auge do exercício de compreensão.

Como destacamos anteriormente, é através da linguagem que temos acesso ao mundo. É na linguagem que o mundo se apresenta. Graças ao fato de termos linguagem é que temos mundo e é esse mundo que vem à fala quando se analisa o material de pesquisa.

\section{Diálogo}

O movimento da compreensão e da interpretação apresenta-se como movimento dialógico que ultrapassa o rigor metodológico. É um acontecer que expressa a estrutura 
ontológica da compreensão através do encontro entre os mundos de sentido. Esse movimento é chamado de círculo da compreensão. Ocorre o distanciamento da metodologia moderna de busca pela verdade. "O círculo da compreensão não é, portanto, de modo algum, um círculo 'metodológico'; ele descreve antes, um momento estrutural ontológico da compreensão" (GADAMER, 2004a, p. 298). Portanto, esse acontecer ontológico necessariamente é diálogo hermenêutico. O mistério que se apresenta na linguagem e a busca pela compreensão do Ser, tem sua experiência efetiva realizada no diálogo. "A partir da conversação que nós mesmos somos, buscamos nos aproximar da obscuridade da linguagem." (GADAMER, 2004a, p. 383). Essa aproximação é constante, pois desde sempre somos linguagem e somente através dela que o mundo se apresenta.

A linguagem como diálogo é resgatada pela hermenêutica filosófica da maiêutica socrática e colocada para além das restrições subjetivas da filosofia da consciência tornando-a verdadeira experiência ontológica. O ser humano deve estar disposto a colocar-se no jogo hermenêutico e revelar sua condição de finitude e historicidade para possibilitar a ampliação da sua compreensão.

A experiência realizada na ATD deve ser pensada como um genuíno diálogo entre os mundos de sentido do pesquisador e do pesquisado. Ao analisar a fala do entrevistado, percebe-se uma infinidade de sentido a ser desvendado. Este contato com este mundo misterioso e desafiador para o pesquisador deve acorrer a partir do círculo hermenêutico, que possui seu autêntico acontecer no diálogo hermenêutico. Mas o que é ou como se entende o diálogo? Gadamer nos explica de uma forma magistral:

O que perfaz um verdadeiro diálogo não é termos experimentado algo de novo,
mas termos encontrado no outro algo que ainda não havíamos encontrado em
nossa própria experiência de mundo. Aquilo que movia os filósofos a criticar
o pensamento monológico é o mesmo que experimenta o indivíduo em si
mesmo o diálogo possui uma força transformadora. Onde um diálogo teve
êxito ficou algo para nós e em nós que nos transformou (GADAMER, 2004b,
p. 211).

A verdadeira experiência acontece no diálogo. Não é na aplicação de uma metodologia fria, engessada, projetada por alguém cujo objetivo é simplesmente replicar seus passos para obter os resultados desejados. Essa seria uma experiência positiva que não transforma. A busca pela verdade não ocorre na experiência positiva, “(...) o caminho para a verdade passa pelo diálogo" (GADAMER, 2004b, p. 211). A experiência com consciência hermenêutica é pensada a partir da condição de abertura, de finitude, sendo essencialmente histórica, sabendo que nada retorna, não se fecha, mas acontece enquanto diálogo aberto. O verdadeiro diálogo nos transforma, por proporcionar algo de novo, algo 
que não esperávamos, que nos surpreendeu e que contribuiu para ampliarmos nossos horizontes de sentido, nossa capacidade de compreensão do assunto a ser estudado.

Estar aberto ao exercício da experiência hermenêutica é ter a consciência dos riscos, dos confrontos, dos questionamentos, dos preconceitos que nos constituem enquanto seres existenciais; do desconforto de não sabermos o que dizer, de termos que rever um posicionamento que achávamos resolvido. De ser uma experiência única que jamais se repete. De sermos experimentados, como nos coloca Gadamer. De estarmos jogados nesse jogo dialógico e nele sermos transformados. É no diálogo vivo que isso é possível e dessa forma é denominado de experiência negativa.

É experimentado, no autêntico sentido da palavra, aquele que tem consciência dessa limitação, aquele que sabe que não é senhor do tempo nem do futuro. $\mathrm{O}$ homem experimentado conhece os limites de toda previsão e a insegurança de todo o plano. Nele consuma-se o valor de verdade da experiência (GADAMER, 2004a, p. 363).

É termos consciência de nossa finitude; é termos consciência que a experiência hermenêutica está diretamente ligada a tradição; que a tradição é linguagem $^{13}$. Eis a verdadeira experiência.

(...) a necessidade de levar a sério a pessoa concreta (com seus preconceitos, suas perguntas específicas, suas biografias e experiências de socialização), mas também de ter presente a história e a linguagem como horizontes desde sempre dados, que condicionam o "vir ao encontro" do outro nem sempre previsível. Sem dúvidas é no diálogo que vivemos a irritação causada pela pergunta do outro e o risco de ver nossas supostas certezas postas em xeque (FLICKINGER, 2010, p. 6).

O diálogo hermenêutico apresenta-se como um movimento importante para ouvirmos as múltiplas vozes. Essa experiência é um momento rico em que diferentes mundos de sentidos, diferentes experiências, se apresentam para debater acerca de um determinado assunto. Nesse movimento complexo de argumentos que envolvem as diversas estruturas de sentido, o conhecimento acontece. Numa pesquisa que visa o puro resultado, esta experiência não acontece por não proporcionar a abertura ao questionamento e a valorização da condição existencial dos sujeitos envolvidos. Este movimento é constante e Gadamer nos ensina que “(...) a capacidade constante de voltar ao diálogo, isto é, de ouvir o outro, parece-me ser a verdadeira elevação do homem a sua humanidade." (2004b, p. 214). Eis um grande desafio para todos os educadores e pesquisadores em tempos tão difíceis que insistem em ridicularizar a valorização do outro e resistem à abertura para o diálogo vivo.

\footnotetext{
${ }^{13}$ Estes conceitos e a relação com a experiência estão presentes em: Gadamer (2004a, p. 363).
} 
Nos parece que a experiência que ocorre na ATD deve e é pensada na perspectiva negativa ${ }^{14}$ que marca e transforma o saber do pesquisador. Caso contrário estaríamos reproduzindo a experiência positiva que perpetua na ciência moderna e que é reproduzida em grande escala nas atuais pesquisas presente nas ciências particulares e que insistem em se fazer presente nas áreas pedagógicas. Portanto, pesquisar é estar aberto aos diferentes mundos de sentido manifestados na linguagem e que se tornam vivos no jogo dialógico.

Na sequência do texto, queremos identificar algumas passagens presentes na ATD que manifestam a aproximação com a hermenêutica filosófica. A teorização dos conceitos presentes na obra de Gadamer feito ao longo do texto, tem esse objetivo.

\title{
7 ATD
}

O pesquisador em apropriação com a ATD necessita ter presente que sua pesquisa está em constante movimento interpretativo e que este acontecer é uma experiência negativa. A interpretação efetivada na escrita provocada pela pesquisa é, necessariamente resultado da fusão dos horizontes de sentido. Não há como se fazer pesquisa, nas trilhas da hermenêutica filosófica, sem ter presente que, a interpretação como resultados da pesquisa é uma experiência causada pelo movimento dialógico presente no círculo hermenêutico, ou seja, pelo círculo da compreensão. As incertezas, as dúvidas, os medos fazem parte desse exercício, pois seus preconceitos são colocados à prova, são desafiados a buscarem o entendimento. Por isso que o exercício hermenêutico é também, um autoconhecimento, um analisar de suas compreensões. Tem uma pista desse entendimento no texto aqui analisado.

\begin{abstract}
Na medida (...) que consegue compreender que todo conhecimento é um autoconhecimento, a partir de um intenso envolvimento no processo da análise, consegue superar sentimentos de medo e frustração, aprendendo a conviver com a insegurança e incerteza sempre associadas a reconstruções com suas marcas de autoria (MORAES; GALIAZZI, 2016, p. 250).
\end{abstract}

Este exercício é o que destacamos como sendo a relação entre diferentes mundos que vem à linguagem. Esse conceito tão caro à hermenêutica filosófica, deve ter uma

\footnotetext{
14 “Assim, a negatividade da experiência possui um sentido marcadamente produtivo. Não é simplesmente um engano que é visto e corrigido, mas representa a aquisição de um saber mais amplo. Desse modo, o objeto com o qual se faz uma experiência não pode ser um objeto escolhido ao acaso. Antes, deve proporcionar-nos um saber melhor, não somente sobre si mesmo mas também sobre aquilo que antes se acreditava saber, isto é, sobre o universal. A negação, em virtude da qual a experiência chega a esse resultado, é uma negação determinada. A essa forma da experiência damos o nome de dialética" (GADAMER, 2004a, p. 359).
} 
preocupação central na ATD. Ao destacarmos a fala de Gadamer que, o ser que pode ser compreendido é linguagem, significa que é na linguagem que as "diferentes vozes" 15 " se manifestam. Os mundos de sentido que vem à fala frutos da cultura, da tradição, do pertencimento a um lugar devem chegar à experiência. Ou melhor: estas questões vão estar presentes no diálogo feito pelo pesquisador e tem que ser analisado com as lentes da hermenêutica filosófica para não correr o risco de se fazer uma análise com a proposta de uma experiência positiva, visando um resultado pura e simplesmente objetivo. Como escreve Gadamer, "Quando se considera a experiência na perspectiva de seu resultado, passa-se por cima do verdadeiro processo da experiência." (2004a, p. 358). A ATD não objetiva a experiência como simples resultado, mas como acontecer.

Nessa linha de raciocínio, identificamos a ideia do acontecer interpretativo na fala dos autores da ATD, destacando a preocupação com o movimento dialógico do ir e vir, ou seja, do movimento dialético presente no círculo hermenêutico: "Na dialética entre ordem e desordem vão emergindo novos entendimentos dos fenômenos investigados, sempre com intensa participação do pesquisador e de suas autorias" (MORAES; GALIAZZI, 2016, p. 249). Os novos entendimentos fazem parte da ampliação do horizonte de sentido, da abertura para os novos saberes, da revisão dos entendimentos. São momentos de crise que ocorrem no processo interpretativo e de escrita.

Ao destacarmos a compreensão como um dos conceitos centrais da hermenêutica filosófica, identifica-se na ATD a preocupação com este conceito.

Pela categorização constroem-se redes de compreensão na linguagem, estabelecendo pontes entre vivências concretas e abstrações elaboradas por meio de conceitos. Também pela categorização, na ATD, reconstroem-se redes conceituais e teóricas relacionadas ao mundo e às culturas (MORAES; GALIAZZI, 2016, p. 245).

Temos o destaque à linguagem, sendo no "médium da linguagem que ocorre toda a nossa experiência do mundo" como destacamos acima.

\begin{abstract}
Na linguagem se estabelece o foco hermenêutico da ATD. O pensamento é possível pela linguagem e por meio dela se constroem conceitos e teorias, tornando compreensíveis os mundos humanos. Constitui elo hermenêutico a partir do qual se concretizam os círculos de compreensões gradativamente mais qualificados nos quais a ATD envolve os pesquisadores (MORAES; GALIAZZI, 2016, p. 254).
\end{abstract}

A passagem que destacamos acima com três conceitos fundamentais da hermenêutica filosófica, a saber: linguagem, mundo e círculos de compreensões. Estes conceitos foram trabalhados ao longo de nosso texto por serem importantes para a

\footnotetext{
${ }^{15}$ Cf. MORAES; GALIZZI, 2016, p. 251.
} 
interpretação hermenêutica acontecer. Ora, compreende-se o mundo a partir da linguagem, ou seja, o mundo vem à fala na linguagem e é no círculo hermenêutico que a compreensão acontece. No contato com o outro, com o diferente, repleto de historicidade, de cultura, é que o horizonte de sentido se amplia e contribui para um melhor entendimento.

A partir das compreensões são possíveis as interpretações, os entendimentos das experiências existenciais de cada sujeito envolvido na pesquisa. É necessário que esta experiência esteja mediada pelo diálogo hermenêutico, genuíno exercício de compreensão e interpretação; momento de revisão e construção do conhecimento. É o sofrimento necessário para a ampliação do horizonte de sentido.

\section{Considerações finais}

O debate de conceitos presentes na base da hermenêutica filosófica, proporciona inquietações para quem se dedica à teorizar e utilizar a ATD como procedimento de análise. Como destacamos ao longo do texto, estes princípios já estão presentes, direta ou indiretamente, na base de sua teoria. Cabe aos pesquisadores se dedicarem seriamente na busca destes pressupostos teóricos para evitar que a ATD se torne mais uma metodologia de simples busca de resultados. Ela é bem mais que isso e o saudoso professor Roque Moraes e, todos os demais teóricos e pesquisadores dessa teoria, possuem essa preocupação em seus escritos e em suas práticas de pesquisa. Ela é uma metodologia rica que merece cada vez mais ser problematizada.

Escrever sobre a hermenêutica filosófica e sua relação com a ATD é um desafio importante e necessário. Sabemos das limitações de problematizar tal assunto em um artigo, mas o intuito não é de fechamento. Pelo contrário: é de dar algumas pistas para provocar novos diálogos e pesquisas acerca do assunto; de chamar a atenção para a necessidade de nos dedicarmos à essa aproximação teórica e metodológica da ATD e da hermenêutica filosófica.

\section{Referências}

ALMEIDA, C. L.S. Hermenêutica e Dialética: dos estudos platônicos ao encontro com Hegel. Porto Alegre: Edipuc, 2002.

FLICKINGER, Hans-Georg. Da experiência da arte à hermenêutica filosófica. In: ALMEIDA, C. L.S.; FLICKINGER, Hans-Georg; ROHDEN, L. (org.). Hermenêutica Filosófica: nas trilhas de Hans-George Gadamer. Porto Alegre: EDIPUCRS, 2000. p. 27-59. 
FLICKINGER, Hans-Georg. A caminho de uma pedagogia hermenêutica. Campinas: Autores Associados, 2010.

GADAMER, Hans-Georg. Verdade e Método I: Traços fundamentais de uma hermenêutica filosófica. Trad. Flávio Paulo Meurer. 6. ed. Petrópolis: Vozes, 2004a.

GADAMER, Hans-Georg. Verdade e Método II: complementos índice. Trad. Enio Paulo Giachini. 2. ed. Petrópolis: Vozes, 2004b.

GRONDIN, J. Introdução à hermenêutica filosófica. Trad. Benno Dischinger. São Leopoldo: Ed. UNISINOS, 1999.

MORAES, R.; GALIAZZI, M.C. Análise textual discursiva: processo reconstrutivo de múltiplas faces. Ciência \& Educação, Bauru, v. 12, n. 1, p. 117-128, 2006.

MORAES, R.; GALIAZZI, M.C. Avalanches Reconstrutivas: movimentos dialéticos e hermenêuticos de transformação no envolvimento com a Análise Textual Discursiva. In: MORAES, R; GALIAZZI, M.C. (org.). Análise Textual Discursiva. 3. ed. Ijuí: Ed. Unijuí, 2016. p. 239-264.

PALMER, R. Hermenêutica. Trad. Maria Luisa Ribeiro Ferreira. Lisboa: Edições 70, 1989.

PÉREZ-ESTÉVEZ, A. Hermenêutica Dialógica. Trad. Antonio Sidekum. Nova Petrópolis: Nova Harmonia, 2013.

ROHDEN, L. Hermenêutica Filosófica. São Leopoldo: Ed. Unisinos, 2002.

Recebido em: 30 de outubro de 2020.

Aceito em: 12 de novembro de 2020. 